\title{
Tipos y manifestaciones de la violencia de género: una visibilización a partir de relatos de mujeres víctimas en Soacha, Colombia
}

\author{
Diana Carolina Tibaná-Ríos \\ Trabajadora Social. Magíster en Desarrollo educativo y social \\ Corporación universitaria Minuto de Dios. Soacha, Colombia \\ https:// orcid.org/0000-0003-2732-3603 • dtibana@uniminuto.edu.co
}

\section{Diana Alejandra Arciniegas-Ramírez \\ Trabajadora Social \\ Corporación universitaria Minuto de Dios. Soacha, Colombia \\ https:// orcid.org/0000-0003-0002-9252 • darciniega6@uniminuto.edu.co}

\section{Ingrid Julieth Delgado-Hernández \\ Trabajadora Social \\ Corporación universitaria Minuto de Dios. Soacha, Colombia \\ https:/ / orcid.org/0000-0002-0523-1321 • idelgadohe1@uniminuto.edu.co}

\section{Resumen}

Este artículo es producto de la investigación "Violencia de género contra mujeres, niñas y adolescentes, en contextos de violencia intrafamiliar: un análisis a partir de los relatos contenidos en expedientes de la Comisaría Segunda de Familia". Se revisaron 277 expedientes de Medida de protección otorgadas en el año 2017. Dichos expedientes contienen la narración de los hechos por parte de la denunciante o víctima. Una vez seleccionada la muestra, mediante la técnica de investigación documental, se recopila la información para, posteriormente, a través del análisis de discurso y contenido, estudiar el uso del lenguaje, poniendo en evidencia los distintos tipos y manifestaciones de la violencia de género. Los resultados permiten identificar que los relatos de las mujeres víctimas no dan cuenta solamente de una violencia intrafamiliar, sino que existe un trasfondo expresado manifestado en tipos de violencia y manifestaciones violentas, propias de la violencia de género.

Palabras clave: Violencia intrafamiliar; Violencia de género; Mujer víctima; Comisaría de familia.

Recibido: 30/12/2019| Aprobado: 03/06/2020

Esta obra está bajo una Licencia Creative Commons Atribución-NoComercial-CompartirIgual $\underline{4.0 \text { Internacional. }}$

Procedencia del artículo: Artículo resultado de la investigación Violencia de género contra mujeres, niñas y adolescentes, en contextos de violencia intrafamiliar: un análisis a partir de los relatos contenidos en expedientes de la comisaría Segunda de Familia en Soacha, 2019. Corporación Universitaria Minuto de Dios, Soacha. 
Tibaná-Ríos, Arciniegas-Ramírez y Delgado-Hernández

\title{
Types and manifestations of gender-based violence: a visibility based on stories of female victims in Soacha, Colombia
}

\begin{abstract}
This article is a result of a research study titled "Gender-Based Violence against Women, Girls and Adolescents, in the Context of Domestic Violence: An Analysis Based on the Stories contained in the files of the Second Family Police Station in Soacha". Two hundred and seventy-seven case files of protection measures granted in 2017 were reviewed. These files contain the narration of the facts from the perspective of the complainant or victim; once the sample has been selected, by means of the documentary research technique, the information is gathered and later the use of language is examined through discourse and content analysis, highlighting the different types and manifestations of gender violence. The results make it possible to identify that the stories of female victims do not only give account of domestic violence, but that there is a background of types and manifestations of violence typical of gender-based violence.
\end{abstract}

Keywords: Domestic violence; Gender violence; Female victims; Family police.

Sumario: 1. Introducción, 2. Metodología, 3. Referentes teóricos conceptuales, 3.1 Violencia Intrafamiliar, 3.2 Violencia de género, 3.3 Tipos de violencias de género, 3.4 Manifestaciones de la violencia de género, 4. Hallazgos, 4.1 Cantidad de casos de violencia, 4.2 Tipos y manifestaciones de la violencia, 5. Conclusiones, 6. Referencias bibliográficas. 


\section{Introducción}

La revista del Instituto Colombiano de Medicina legal: Forensis. Datos para la vida, para el año 2017, permite evidenciar en Colombia un total de 27.538 casos de violencia intrafamiliar a nivel nacional, de los cuales 16.463 casos corresponden a violencia contra la mujer, aproximadamente $60 \%$ de los casos; las edades en las que más se presentó el maltrato están entre los 20 y 24 años, mujeres en el ciclo vital de juventud y adultez. El Municipio de Soacha ${ }^{1}$ tuvo la más alta tasa de atención en clínica forense, por casos de violencia, registrando entre ellos 1.410 casos de violencia de pareja y 338 casos de violencia sexual (Romero-Quevedo 2017).

Partiendo de lo anterior, en términos culturales la política pública de mujer y equidad de género del Municipio describe que: "Culturalmente Soacha se desarrolla con altos índices de violencia contra las mujeres" (Acuerdo 25 de 2015, p. 2), violencia de género que se fundamenta en elementos socioculturales patriarcales y machistas que legitiman la violencia como recurso de obediencia y sumisión femenina.

También esta política amplía el ámbito económico en el que las mujeres se encuentran inmersas, indicando que "en contextos como el de nuestro Municipio crece paulatinamente el fenómeno denominado feminización de la pobreza que se traduce en que las mujeres son las más empobrecidas entre todas las personas"' (Acuerdo 25 de 2015), debido a la sobrecarga de trabajo y la jefatura femenina asignada en torno a la manutención de ellas, sus hijos, hijas, adultos mayores, así mismo de personas enfermas (p.5).

En el entorno político es considerable abordar dos perspectivas: la participación de las mujeres en espacios de decisión y la respuesta gubernamental a problemáticas o necesidades de esta población. Si bien las mujeres del municipio ejecutan acciones para modificar las relaciones de poder y el sistema simbólico que incide en el desarrollo, considerando los derechos humanos de las mujeres y niñas, aún deben sobreponerse a la oposición respecto al acceso de recursos o cargos con poder de decisión (Acuerdo 25 de 2015, pp. 2-3). Teniendo en cuenta el crecimiento demográfico de la población femenina, para el censo del año 2005, Soacha contaba con una cantidad poblacional de 398.295 habitantes, de los cuales 48,8\% eran hombres y 51,2\% mujeres. Posterior al año 2015, los porcentajes evidencian la prevalencia del género femenino con un $51 \%$ acorde a la población total en el municipio (Concejo Municipal de Soacha, 2015). Acorde a lo anterior, "la respuesta del Estado es bastante deficiente, no existen políticas efectivas ni aplicación

1 Soacha cuenta con una división de zona urbana de $17 \mathrm{Km}^{2}$ y zona rural de $160 \mathrm{Km}^{2}$, para un total de 187 $\mathrm{Km}$. Limita al suroccidente con la capital del país, Bogotá. Este municipio cuenta con 346 barrios y un total de 634.660 habitantes según registros de la alcaldía. 
de la reglamentación de no violencia contra la mujer. En algunos casos existen profusas medidas, pero un incumplimiento sistemático de las mismas" (Acuerdo 25 de 2015, p. 3).

En general, pese a los avances en términos de instrumentos estatales para atender la violencia de género, las desventajas de las mujeres son evidentes en diferentes esferas sociales, en las que a pulso se abren camino para hacer frente a los estereotipos de género avalados por la cultura hegemónica patriarcal, manifiesta en contextos macro y micro incluida la familia.

La violencia intrafamiliar incluye a toda persona que conviva en el mismo lugar de residencia, o que sea excompañero, excónyuge, con el cual se tenga una unión por medio de los hijos; también, enmarca y contiene la violencia contra niños, niñas y adolescentes. En caso de que estos agravios se presenten en la pareja, se considera violencia conyugal, no obstante, en la mayoría de las situaciones, las potenciales víctimas son aquellas pertenecientes al género femenino, por lo cual se requiere reconocer y buscar medios para visibilizar que la violencia de género se encuentra inmersa en los casos de violencia intrafamiliar. Así como diferenciar estas dos formas de violencia en aras de encauzar acertadamente los procesos de prevención y atención.

La violencia ejercida contra la mujer en contextos familiares comprende distintos tipos de agresiones, enunciados por la Ley 1257 de 2008, la cual contempla claramente el daño físico, psicológico, patrimonial, económico y sexual; sin embargo, a partir de la revisión teórica se incluyeron violencias tales como la vicaria, simétrica y emocional que, en general, ponen en desventaja a la mujer, trayendo consigo afecciones a su integridad. Aunado a ello, las manifestaciones permiten develar una cultura dominante en contra de la mujer, instrumentalizada también por medio del lenguaje. Para determinar las diferentes manifestaciones se aprehende de una estrategia gestada en México por el IPN (Instituto Politécnico Nacional, Gestión de perspectiva de género) donde, a partir de una investigación sobre violencia de pareja, se establecen 31 conductas alarmantes que indican violencia y son relevantes para identificar dentro de los relatos elementos aparentemente tácitos.

Mediante el análisis de discurso y contenido de los expedientes, se reconocen los significados simbólicos o instrumentales recibidos por las mujeres víctimas de cualquier tipo de violencia en sus diferentes expresiones, de modo que, con estas legitimaciones, se abre el panorama para divisar la violencia contra la mujer y reforzar así las acciones desde entidades competentes, como las Comisarías en el municipio de Soacha.

Actualmente el municipio cuenta con tres Comisarías de Familia las cuales se dividen por comunas y corregimientos según jurisdicción territorial; en específico, la Comisaría Segunda brinda atención a las comunas 2, 6, así como al corregimiento 1, de las 
seis comunas y dos corregimientos en el municipio. Partiendo de esta premisa, es importante mencionar que las comunas corresponden a zonas urbanas de la cabecera municipal y el corregimiento pertenece a la zona rural, en este último, dada la distancia se evidencia una limitante en el acceso a entidades como la Comisaría de Familia. Es de recalcar que las Comisarías de Familia son el primer lugar para que los miembros integrantes de la familia accedan a la Justicia Familiar, en busca de garantías y el restablecimiento de sus derechos conculcados en contexto de violencia intrafamiliar.

\section{Metodología}

Enfoque de género o perspectiva de género es una herramienta de análisis teórica y metodológica (Corporación Sisma Mujer, 2010), para visualizar la producción y reproducción de las relaciones de género, la desigualdad y la jerarquía entre hombres y mujeres (p. 62). Por ello, se estima como un enfoque transversal para el abordaje de la violencia de género en el contexto Soachuno, (Gómez, Murad y Calderón, 2019), entendiendo que "esta perspectiva concibe la violencia contra las mujeres como un abuso de poder en una estructura social que favorece que los hombres agredan a las mujeres" (p. 22), retomando elementos que permiten analizar los tipos y manifestaciones de esta violencia.

El método de investigación es cualitativo, el cual "proporciona profundidad a los datos, dispersión, riqueza interpretativa, contextualización del ambiente o entorno, detalles y experiencias únicas" (Hernández-Sampieri, Fernández-Collado y Baptista-Lucio, 2014). Dicho esto, se adquiere conocimiento a partir de los relatos y experiencias vividas en las relaciones cotidianas de las víctimas con medida de protección en la Comisaría Segunda en Soacha.

La perspectiva paradigmática es la hermenéutica, definida como el arte de interpretar textos para determinar su verdadero sentido (Zúñiga-Espitia, 2005), enfatizada en la óptica del autor (Ricoeur, 2006), que indica que, "la escritura es la manifestación íntegra del discurso" (p. 38.), es decir, que lo hallado en la revisión documental revive acontecimientos para profundizar sobre contextos socioculturales que se conservan en el tiempo.

Respecto al tipo de investigación, se retoma a Hurtado de Barrera (2010), con el nivel de profundidad analítico que "pretende encontrar pautas de relación internas en un evento para llegar a un conocimiento más profundo de este, más que la mera descripción [...] la investigación analítica intenta desentrañar lo que está más allá de lo evidente" (p. 134). Esto, desde los hallazgos conceptuales y testimonios de hechos violentos, 
puntualizando elementos tácitos al abordar la violencia de género hacia la mujer, en contextos de violencia intrafamiliar.

La selección de la muestra se determina por técnicas de muestreo no probabilísticas, cualitativas, según (Hernández-Sampieri et al., 2014), mediante la muestra homogénea combinada con casos tipo, ya que los expedientes tienen perfiles semejantes y resaltan situaciones en particular del grupo social; además "el objetivo es la riqueza, profundidad y calidad de la información, no la cantidad ni la estandarización” (pp. 387-388). Así, de 377 casos recibidos en el año 2017, 277 poseen estas características: Mujeres, niñas y adolescentes violentadas, que narran dichos hechos al iniciar el proceso de medida de protección, los que quedan consignados y escritos en un formato institucional; casos de agresión ejercida por un integrante del círculo familiar, con vínculos de consanguinidad o afinidad, que corresponden a las Comunas 2, 6 y Corregimiento 1 de Soacha,

La técnica de recolección de información es la investigación documental definida como "aquella que combina diferentes fuentes, pueden ser trabajos basados, documentos recogidos, archivos oficiales o privados, son el insumo principal, textos a los cuales se les "entrevista" por preguntas que guían la investigación, y se "observan con la misma intensidad". (Cifuentes-Gil, 2014, p. 77).

Para analizar los datos cualitativos se determinan "técnicas de análisis de contenido y discurso". El análisis de contenido en (Bereleson \& Grawitz, 1976 citado por Hurtado de Barrera, 2010), "realiza una descripción objetiva, sistemática y cuantitativa del contenido manifiesto, de los cuales se pretende obtener una interpretación" (p. 1176), y, el análisis de discurso no solo abarca la lectura exhaustiva del lenguaje escrito, sino evidencia las relaciones constituidas mediante los sistemas de comunicación verbal y no verbal de los testimonios.

Lo que se indaga no es tanto el "qué" se dice sino más bien el "cómo" se dice"; el nivel de abstracción en la técnica es, el literal: "estudia el sentido de las palabras, va dirigido a determinar lo que se quiere decir con la comunicación. (Armony, 1997 citado por Hurtado de Barrera, 2010, p. 1177).

Las técnicas para el procesamiento de la información se usaron de manera complementaria con el apoyo del software ATLAS.Ti, según el cual el investigador/a agrega el documento que contiene la información transcrita y empieza a codificarlo acorde al esquema que haya diseñado (Hernández-Sampieri et al., 2014). 


\section{Referentes teóricos conceptuales}

\subsection{Violencia intrafamiliar}

El asunto que interviene la Comisaría segunda de familia de Soacha es la Violencia intrafamiliar, definida desde dos perspectivas por Quintero-Velásquez (2007), quien entiende la violencia familiar como aquella agresión real o simbólica, que afecta directamente o no a los integrantes de la familia, "resultado del establecimiento de transacciones inequitativas entre diversos, con ejercicio de poder y el desconocimiento de la diversidad" (p. 124). También hace referencia a la violencia intrafamiliar como actos agresivos en el ámbito doméstico, reconocidos por el Estado y penalizados por la ley: "Es una conducta aprendida a través de los procesos de socialización, por lo cual es modificable. Se constituye en un obstáculo para un desarrollo equitativo en igualdad de oportunidades" (p. 124).

Estas acepciones se establecen como diferentes, no obstante, la violencia familiar continúa siendo un problema social que afecta mayormente a la figura femenina en las relaciones familiares. De este modo, se propone la lectura en el documento sobre la Violencia Intrafamiliar (VIF), como todo tipo de acción u omisión agresiva intencional que perjudique la salud mental y física de un integrante del núcleo familiar, bien sea que se conviva o no en el mismo hogar.

\subsection{Violencia de género}

Según Varela (2015), la violencia de género es aquella que sufren las mujeres y que tiene sus raíces en la discriminación histórica y la ausencia de derechos que han sufrido y continúan sufriendo en muchas partes del mundo, sustentada sobre una construcción cultural (el género), basada en la cosmovisión binaria a partir de los cuerpos sexuados (p.214).

En primera instancia, se determina esta violencia como un atropello contra la integridad de la mujer por razones de jerarquía y poder, entre mujer y hombre. En Colombia la Ley 1257 de 2008 (por la cual se dictan normas de sensibilización, prevención y sanción de formas de violencia y discriminación contra las mujeres) define la Violencia contra la mujer como: "cualquier acción u omisión, que le cause muerte, daño o sufrimiento físico, sexual, psicológico, económico o patrimonial por su condición de mujer [...] en el ámbito público o en el privado."; por otro lado, Gálvez-Montes (2011) señala que esta violencia se presenta en el escenario íntimo de las relaciones, en la pareja, el matrimonio y la familia, donde se somete la mujer al jefe del sistema patriarcal (p. 18). 
Para efectos de interpretación, se entiende por violencia de género toda acción u omisión agresiva intencional, bajo la premisa de relaciones de poder asimétricas, donde el hombre o la figura masculina asume el dominio conforme al sistema patriarcal, afectando directa e indirectamente al género femenino, específicamente en el contexto familiar, causando daños de tipo físico, psicológico, sexual, emocional, vicario, económico y patrimonial.

Teniendo en cuenta el desarrollo conceptual de violencia intrafamiliar y violencia de género, "utilizar violencia familiar para referirse a la violencia contra las mujeres es un error puesto que no son sinónimos" (Varela, 2015, p. 213), dado que la primera hace referencia al entorno, espacio en el que se efectúa la agresión, y la segunda se refiere hacia el sujeto en específico al que va dirigida la agresión.

\subsection{Tipos de violencias de género}

Para establecer los tipos de violencia de género, se toma como referente lo dictado en la Ley 1257 de 2008 en el artículo N ${ }^{o}$ 3: el daño, psicológico, físico, sexual y patrimonial; sin embargo, emergieron otros tipos de violencias durante la revisión teórica: violencia emocional, económica, vicaria y simétrica.

Violencia Emocional, acorde a lo descrito por Sanmartín-Esplugues (2007)

No son las secuelas psicológicas que se siguen de los otros tipos de daño. No son los efectos psicológicos negativos que experimenta la víctima de palizas reiteradas. Se trata de cualquier omisión $\mathrm{u}$ acción que causa o puede causar directamente un daño psicológico. Suele valerse del lenguaje, tanto verbal como gestual. Está paradigmáticamente representada por el insulto. (p.10).

De igual modo, es importante mencionar que dicho daño al ser verbal minimiza el daño real que se ocasiona en la víctima, no obstante, la violencia emocional se diferencia de la psicológica debido a que esta última afecta de manera más profunda a la víctima.

El Daño o violencia psicológica, es reconocida en el apartado "a" de la Ley 1257 de 2008, como:

Consecuencia proveniente de la acción u omisión destinada a degradar o controlar las acciones, comportamientos, creencias y decisiones de otras personas, por medio de intimidación, manipulación, amenaza, [...] o cualquier otra conducta que implique un perjuicio en la salud psicológica, la autodeterminación o el desarrollo personal. 
Tibaná-Ríos, Arciniegas-Ramírez y Delgado-Hernández

En la misma ley, se define en el apartado " $b$ " la Violencia y/o Daño o sufrimiento físico como el "riesgo o disminución de la integridad corporal de una persona", de manera que, somete a la otra persona mediante la imposición de la fuerza, puesto que, de manera represiva, se ejerce dominio y control a través de los golpes que atentan contra la salud física, generando enfermedades e incluso la muerte. La Organización Panamericana de la Salud (1998) refiere que la violencia física: “Ocurre cuando una persona que está en una relación de poder con respecto a otra, le infringe o intenta infligir daño no accidental, por medio del uso de la fuerza física o algún tipo de arma" (p. 11).

El Patrimonio, se entiende como los bienes muebles e inmuebles que se adquieren o poseen, incluidos los objetos y documentos de uso personal. En el artículo 3 de la Ley 1257 de 2008, apartado " $\mathrm{d}$ " se indica que la Violencia y/o Daño Patrimoniales "es toda pérdida, transformación, sustracción, destrucción, retención, restricción o distracción de objetos, instrumentos de trabajo, documentos personales, bienes, valores, [...] destinados a satisfacer las necesidades de la mujer"; es habitual asociar la violencia patrimonial con la económica, pero en la presente investigación se entenderán de manera distinta. A la violencia económica Duque y Vieco (2012) la denominan como el "Abuso económico", basado en "Controlar el acceso de toda la familia al dinero, se hace chantaje y control de los ingresos familiares, con el fin de mantener autoridad y ganar poder dentro del grupo" (p. 30). De este modo, se retiene o maneja el dinero, impidiendo el goce pleno de la retribución por el trabajo o imponiendo la forma de inversión de éste, lo cual genera una coerción en lo que respecta al disfrute del mismo; en el caso de no poseer un salario, el agresor restringe el suplemento económico, con la intención de no suplir sus necesidades básicas.

La Violencia Vicaria es un tipo de violencia no reconocida en el contexto colombiano, considerada como la forma más extrema de la violencia de género. Vaccaro (2018) la define como "Violencia contra la mujer [...] cuya máxima expresión es el asesinato de las hijas y los hijos. El maltratador sabe que dañar, asesinar a los hijos/hijas, es asegurarse de que la mujer no se recuperará jamás. Es el daño extremo" (p. 10). En esta violencia, el agresor, aunque sea el padre, visualiza a los menores como el objeto directo para dañar de la manera más fuerte a la madre. La separación de pareja es una etapa en la que aumenta la violencia vicaria, ya que el menor legalmente debe compartir espacios de afectividad con el otro progenitor, estos espacios abren puerta a que el agresor utilice al menor como instrumento para ocasionar daños o molestias a la víctima.

La autora Falcón-Caro (2002) muestra un tipo de violencia particular denominado Violencia Simétrica o violencia agresión que se suscita "cuando ambos están en una situación de desigualdad, desafío, y uno intenta imponerse al otro. La mujer, aunque sigue siendo la víctima, continúa la pugna, no se somete al hombre. Son peleas interminables donde prima la devolución constante de golpes" (p. 33). Este tipo de violencia se distingue 
Tibaná-Ríos, Arciniegas-Ramírez y Delgado-Hernández

principalmente por un carácter de enfrentamiento constante y simultáneo, donde la mujer procura reivindicar su estatus en relación con el hombre, por lo tanto, la posición que asume la mujer es de defensa propia ante su agresor, teniendo en cuenta algunas características establecidas en la Ley 599 de 2000, artículo 32, sobre la legítima defensa, que tiene como objetivo garantizar la plena defensa de los derechos de las personas.

\subsection{Manifestaciones de la violencia de género}

Son aquellas conductas puntuales que se evidencian en el trayecto de las agresiones en contextos de violencia intrafamiliar y contra la mujer específicamente; se pueden observar claramente en el violentómetro (Figura 1), herramienta originada en la unidad de género del Instituto Politécnico Nacional de México (2009) donde indagaron sobre las relaciones en pareja de 14.000 jóvenes estudiantes, concluyendo que hombres y mujeres alguna vez habían experimentado estos comportamientos por parte de sus parejas. Con base en ello, se diseñó un material gráfico para identificar las expresiones violentas, medir el grado de intensidad y direccionar el caso a la entidad competente.

Figura 1. Violentómetro.

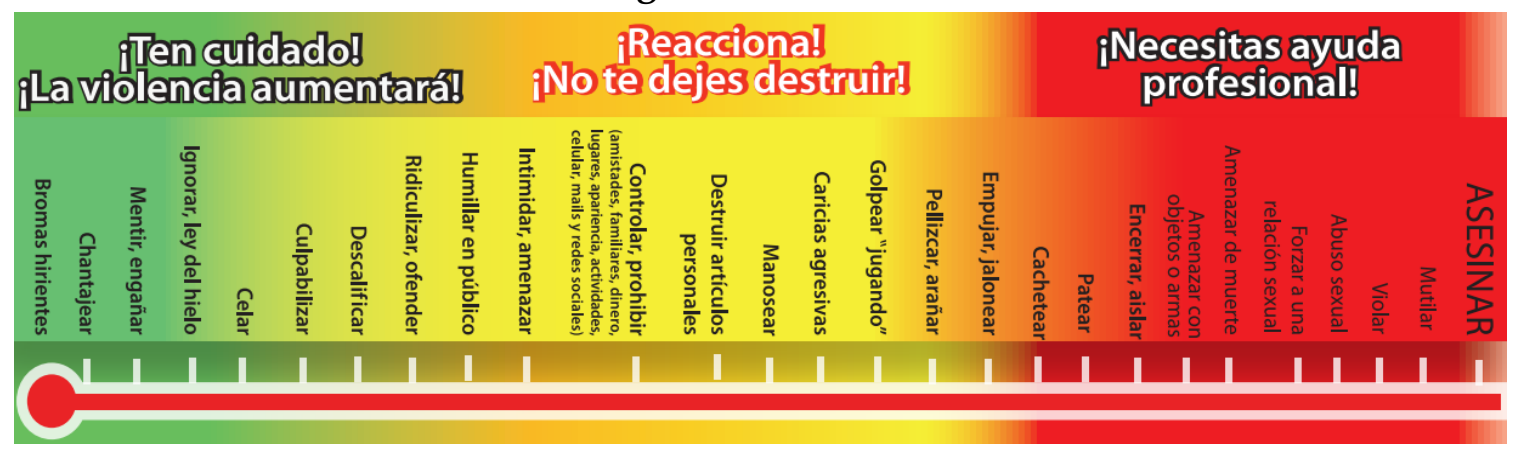

Fuente: Instituto Politécnico Nacional de México, 2009.

Bromas hirientes: Burlas ofensivas con el fin de ridiculizar, aparentemente tras el humor.

Chantajear: Forma de manipular a conveniencia del agresor, con el fin de persuadir hasta cumplir su deseo.

Mentir, Engañar: Decir lo contrario a la realidad, para hacer creer alguna afirmación a conveniencia.

Ignorar, ley del hielo: Hacer caso omiso a la opinión de alguien, anulándolo con la indiferencia.

Celar: Sospecha excesiva de infidelidad (Gálvez-Montes, 2011); o celotipia, que es: "la inseguridad que envuelve a muchas parejas al no poder ejercer un control sobre el otro" (Rodríguez-López et al., 2017).

Culpabilizar: (Gálvez-Montes, 2011) refiere que se quita "de encima la responsabilidad y carga la culpa a la víctima (todo va mal por culpa de ella)” (p. 35). 
Descalificar: Suprimir el valor de la mujer, anulando sus capacidades.

Ridiculizar, ofender: Sátira hacía la víctima para desacreditarla y desprestigiarla.

Humillar en público: Expresiones incómodas que minimizan a la persona, donde el agresor se siente con autoridad de denigrarla.

Intimidar, amenazar: en la intimidación "el hombre asusta a su mujer con miradas, gestos y gritos." y Amenazas "de quitarle los niños a su esposa, quitarle la asistencia alimentaria etc." (Duque y Vieco, 2012)

Controlar, prohibir: (amistades, familiares, dinero, lugares, apariencia, actividades, celular, mails y redes sociales): Posesión de todas las áreas sociales y personales del individuo además de vigilar y dominar la inversión del dinero; no permitir la concurrencia a ciertos lugares, criticar la forma de expresar de la víctima influyendo sobre sus decisiones, y la revisión controladora de las conversaciones personales o suplantación a través de redes sociales.

Destruir artículos personales: (Gálvez-Montes, 2011) “Dar puñetazos y patadas a las puertas y paredes, tirar al suelo o por la ventana objetos personales, etc." (p. 25).

Manosear: Toquetear arbitrariamente a la víctima de manera lasciva y lujuriosa.

Caricias Agresivas: libidinosamente, tocar o rozar causando daño, mediante la brusquedad y fuerza.

Golpear "jugando": Tras la apariencia de "juego", se evidencian golpes intencionados.

Pellizcar, arañar: Causar dolor y secuelas, mediante el apretón de la mano conteniendo la piel de la víctima.

Empujar, jalonear: Ejercer fuerza, con la intención de mover o reducir a la persona; jalonear, se refiere a tirar del cuerpo o prenda a una persona, hacia sí, para dominar sobre ella.

Cachetear: Dar golpes en la cara, con la mano abierta, hacia la parte de los pómulos.

Patear: Usar los pies de forma violenta, para causar daño físico a la víctima o para romper, dañar objetos de manera intencional.

Encerrar, aislar: Impedir "contacto con familia, compañeros de estudio. Se busca controlar cada aspecto de la vida de la víctima, tiempo, actividades" (Duque y Vieco, p. 30).

Amenazar con objetos o armas: (Gálvez-Montes, 2011) "guardar armas en la casa con el fin de asustar a ella y a sus hijos o a sus seres queridos (hijos, otros familiares...)" (p. 26).

Amenazar de muerte: Intimidar a la víctima con atentar contra su vida, a través de advertencias directas de muerte.

Forzar relación sexual: Obligar a la persona a sostener encuentros sexuales, primando la satisfacción de placer del agresor sin consentimiento de la víctima, usando la fuerza.

Abuso sexual: Es toda actividad sexual realizada hacia una persona, contra su voluntad.

Violar: "Toda penetración por ano, boca o vagina usando la fuerza o intimidación" (Gálvez-Montes, 2011). 
Mutilar: Cortar el cuerpo de la víctima, para causar sufrimiento y materializar su poder sobre el mismo, "comprende todos los procedimientos que, de forma intencional (...), alteran o lesionan los órganos genitales femeninos" (Organización Mundial de la Salud, 2020).

Asesinar: Acto violento que le dé fin a la vida de la persona de manera premeditada o impulsiva, también considerado feminicidio en casos de mujeres.

Escupir: Lanzar saliva como símbolo de menosprecio, para devaluar a la persona.

Amenaza con dañar a la familia: Advertencia de atentar contra la familia de la víctima, como medio de manipulación y desestabilización.

Castigo a los hijos por enojo con la víctima: Colocar a los menores como objeto intermedio en la disputa, para causar daño a la víctima mediante los hijos/as.

Destruir patrimonio: Dañar objetos, artículos del hogar, televisores, puertas, ventanas o cualquier ornamentación de la víctima y su vivienda.

A modo de glosario se presentan las definiciones de las diferentes manifestaciones de la violencia aportadas por el violentómetro, expuesto previamente; sin embargo, a lo largo de la lectura y análisis emergieron patrones de conductas reiteradas que se incluyeron por considerarlo pertinente. Dichas definiciones aportan una orientación objetiva en la lectura y análisis de las narraciones contenidas en los expedientes, ya que en la mayoría de los mismos se evidencian similitudes en la forma como el agresor presenta las agresiones contra la mujer.

Las manifestaciones de la violencia guardan estrecha relación con los tipos de esta; cabe aclarar que es un desatino intentar encasillar siempre las mismas manifestaciones en tipos de violencia específicos, ya que se pueden cruzar o variar en su representación por la realidad presentada, que es dinámica y cambiante.

\section{Hallazgos}

\subsection{Cantidad de casos de violencia}

A continuación, se desarrolla la discusión en torno a los resultados encontrados. Para ello, se realizó una lectura intensiva y extensiva de 277 casos de violencia de género contra la mujer presentados en el año 2017; el acceso a los registros fue autorizado por la Comisaría Segunda de Familia de Soacha.

De acuerdo con lo anterior y como se evidencia en la Tabla 1, el daño emocional fue el tipo de violencia que más se presentó en los relatos escritos, con una representatividad de 202 casos, seguidos por 159 de violencia física, 94 psicológica, 48 patrimonial, 65 vicaria, 33 simétrica, 28 económica, y 16 de tipo sexual. Esta cuantificación de casos se realizó a partir de los tipos de violencia identificados que operan como categorías del proceso 
Tibaná-Ríos, Arciniegas-Ramírez y Delgado-Hernández

investigativo. Asimismo, en la Tabla 2, se refleja la recurrencia en términos de las manifestaciones de violencia, encabezando en cantidad la declarada como intimidaciones y amenazas con una representatividad de 94 casos, seguidas de las amenazas de muerte con 85 casos, 52 empujones-jaloneos, 50 situaciones de celos, y la amenaza con objetos u armas con una recurrencia de 49 casos.

Tabla 1. Cantidad de casos por tipo de violencia

\begin{tabular}{|c|c|c|c|c|c|c|c|c|}
\hline $\begin{array}{l}\text { Tipo de } \\
\text { violencia }\end{array}$ & 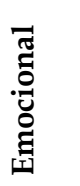 &.$\frac{\Xi}{9}$ & 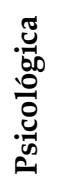 & 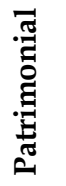 & 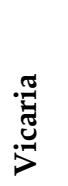 & 苞 & 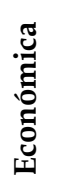 & 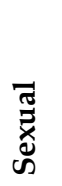 \\
\hline $\begin{array}{c}\text { Cantidad } \\
\text { casos }\end{array}$ & 202 & 159 & 94 & 48 & 65 & 33 & 28 & 16 \\
\hline
\end{tabular}

Fuente: elaboración propia.

Tabla 2. Cantidad de casos por manifestación de violencia presentada

\begin{tabular}{|c|c|c|c|c|c|c|c|c|c|c|c|c|c|}
\hline 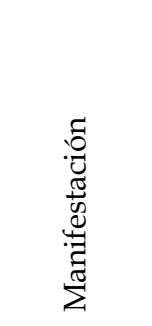 & 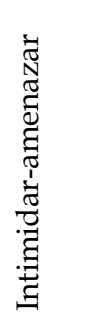 & 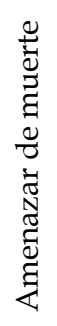 & 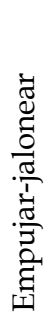 & $\frac{\bar{\pi}}{0}$ & 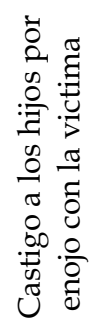 & 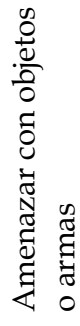 & 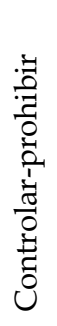 & 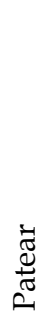 & 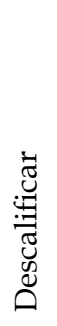 & 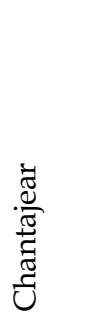 & 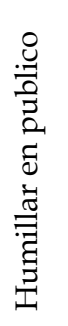 & 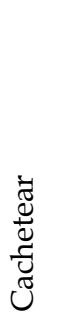 & 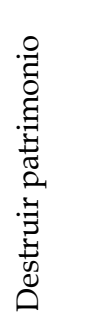 \\
\hline Cantidad & 94 & 85 & 52 & 50 & 29 & 49 & 29 & 29 & 26 & 24 & 24 & 18 & 17 \\
\hline 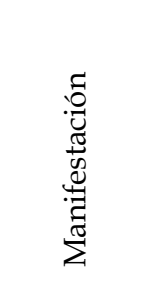 & 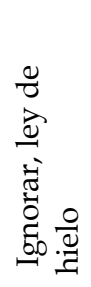 & 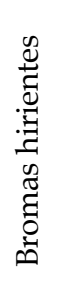 & $\frac{\stackrel{\vec{\jmath}}{\circ}}{\stackrel{0}{>}}$ & 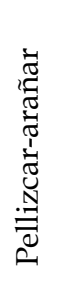 & 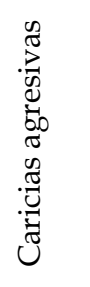 & 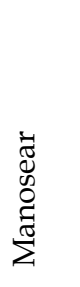 & 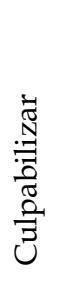 & 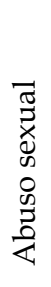 & 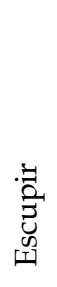 & 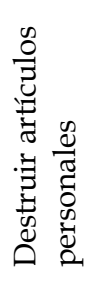 & 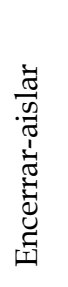 & 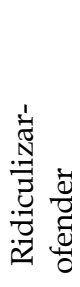 & 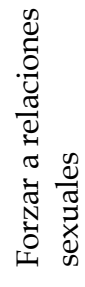 \\
\hline Cantidad & 2 & 2 & 3 & 3 & 4 & 5 & 6 & 8 & 9 & 9 & 12 & 17 & 17 \\
\hline
\end{tabular}

Fuente: elaboración propia.

Si bien estas representaciones gráficas muestran de manera aislada los tipos y manifestaciones de la violencia, es imperativo reconocer la complejidad de dichas categorías dada su multicausalidad. Es así como en un solo relato se pueden encontrar variedad de tipologías y manifestaciones. Por ello el ejercicio de categorización se constituye como un proceso dinámico en el que se yuxtaponen tendencias y relatos, tal y como se muestra a continuación. 


\subsection{Tipos y manifestaciones de la violencia}

Tipo de violencia simétrica: ¿perpetración recíproca de la violencia?

La violencia simétrica según Falcón-Caro (2002) es "una situación de desigualdad, de desafío, en el que uno intenta imponerse al otro", esta violencia se visibiliza como una reacción de defensa propia, que ejerce la mujer frente a una situación agresiva que impone el agresor sobre ella; por lo general en esta violencia prevalece una situación constante de agresiones verbales entre la pareja: "comenzó a mandarme y a gritarme y yo le contesté" (Luz, 34 años, Julio 2017) ${ }^{2}$ hasta llegar a las agresiones físicas, "me mandó un puño y yo también le pegué" (Patricia, 52 años, febrero 2017). Las agresiones pueden iniciar desde insultos mutuos y partir de allí escalar hacia otras formas e intensidad de la agresión.

En los relatos, como los presentados a continuación, se evidencia que la mujer víctima recurrente de violencia por parte del hombre, trasciende la actitud pasiva y reacciona de la misma forma violenta hacia él. Este tipo de violencia se manifiesta por medio de: cachetadas "cuando me abofeteó yo reaccioné, me levanté y como pude le di un puño" (Carmen, 42 años, 25 marzo 2017), "fue ahí donde me pegó una cachetada y yo lo cogí del buzo y en el forcejeo creo que le rasguñé" (Paula, 30 años, mayo 2017); también con pellizcos y arañazos: "me empezó a rasguñar y a pellizcar el brazo derecho, luego yo hice lo mismo" (Fernanda, 23 años, diciembre 2017); empujar y jalonear: "yo le dije que no me tratara mal, que yo no quería pelear y ahí me empujó y yo también lo empujé y ahí se vino encima mío a pegarme puños y yo me defendí y ahí le pegué" (María Alejandra, 21 años, marzo 2017).

Sobre este tipo de violencia, cabe resaltar que no se pretende minimizar la ejercida contra la mujer, ni justificar la acción agresiva desde la víctima o el victimario, lo que sí se busca es dar a conocer la presencia de esta tipología, dada la reciprocidad de la conducta, lo cual cobra sentido cuando se ve una implicación o afectación mutua dentro del ciclo violento.

\section{Tipo de violencia vicaria: daño a la maternidad}

En Colombia, la violencia vicaria no es reconocida como un tipo de violencia contra la mujer pero, como lo define Vaccaro (2018), es una de las violencias más extremas que se presenta en el interior del hogar contra las mujeres, en ella el agresor atenta contra la integridad de los niños, niñas o adolescentes usualmente hijo-as de la mujer: "lo llamé para que me entregara a mi hijo y me lo entregó en un estado enfermo, no le había dado de comer y la ropa le estaba oliendo a nicotina y a marihuana, lo cual me parece una falta

2 Las fechas dispuestas posterior al relato corresponden a la fecha en que ocurrieron los hechos denunciados por mujeres víctimas de violencia y consignados en el proceso de medida de protección, dentro de los expedientes de la Comisaría segunda de Soacha. Se presenta de la siguiente forma: pseudónimo de la víctima, edad y fecha del suceso. 
Tibaná-Ríos, Arciniegas-Ramírez y Delgado-Hernández

de respeto" (Juana, 23 años, agosto 2017). Incluso, en muchos de los casos, el agresor realiza amenazas contra la vida de los hijos de la víctima, buscando así generar una afectación semidirecta, de tal forma que le sea difícil recuperarse: "él se mete con mis hijos, dice que me va a dar donde más me duele que es con ellos" (Giselle, 28 años, febrero 2017). Las amenazas en esta dimensión generan en las madres un temor por perder a sus hijos: "amenazó a la niña con el hecho de si ella dice algo, lo mismo le puede pasar a ella y le mostró el arma con la que dice me va a matar" (Carol, 34 años, mayo 2017). Para los victimarios resulta fácil amenazar con hacer daño a los niños y niñas, o hacerles el daño, sin importar que sean hijos de él también: "tengo mucho miedo con mis hijos y conmigo misma, dice que me los va a picar, que si yo lo demandaba que él me los iba a quitar" (Vanessa, 22 años, febrero 2017).

En lo analizado, no se evidenció algún caso donde los límites del maltrato hacia un hijo-a lo llevaran a la muerte, pero en muchos escenarios de violencia vicaria la intención del agresor es acabar con la vida de este y así establecer un daño emocional grave a la mujer.

\section{Tipo de violencia patrimonial: castigo material.}

Los bienes muebles e inmuebles son elementos que se suelen adquirir en la sociedad conyugal, hacen parte de la vida en pareja y ocupan un espacio físico o emocional, representan un esfuerzo mancomunado o individual para su obtención, por ende, una inversión monetaria. Dañar estos recursos es un mensaje hacia la víctima y una agresión "material", se identifican argumentos del agresor que se manifiestan al atribuirse el rol de propietario sobre el patrimonio y, así mismo, el derecho de disponer sobre estos, anulando la facultad de decisión de la mujer al respecto.

En ocasiones este tipo de violencia se evidencia al restringir el uso de ciertos recursos muebles e inmuebles imprescindibles en la cotidianidad, por ejemplo: "me abrió la puerta me dijo que no me bañara en el baño de él, que estaba mamado de mantenerme ya que yo estaba durmiendo en el cuarto del niño porque él me sacó del cuarto matrimonial" (Milena, 26 años, 02 julio 2017). Nuevamente, es de resaltar el poder sobre los recursos físicos de la pareja, limitando el acceso a estos. En las relaciones conyugales influye trascendentalmente el asunto de los bienes y el patrimonio, donde las relaciones de poder asimétricas son evidentes y visibles, a favor del hombre que interioriza su rol de "dueño" en el hogar, asumiendo el control por sobre la mujer, invalidando su aporte y aplicando la frase "si no es para mí no es para nadie" pero en términos de aquellos bienes en común. 
Tibaná-Ríos, Arciniegas-Ramírez y Delgado-Hernández

En relación con este tipo de violencia se hallan dos manifestaciones latentes: destruir artículos personales de la mujer y destruir el patrimonio; en la primera es común encontrar narraciones donde el ataque hacia los recursos se focaliza en aquellas piezas de uso frecuente e individual por parte de la mujer: "empezó a romperme las cosas, me rompió el espejo del tocador, la plancha del cabello, mis gafas y otras cosas" (Cledis, 42 años, enero 2017). En la segunda manifestación, en torno a la destrucción del patrimonio, regularmente se efectúa a las posesiones inmuebles como la vivienda: “ese día en la noche acuchilló las paredes del apartamento que son con papel de colgadura y pasó el cuchillo por la mayor parte que pudo además en tres baldosas del piso les pegó con el martillo" (Claudia, 35 años, febrero 2017).

En esta violencia se hace irrelevante el trabajo de la mujer por mantener $u$ obtener los bienes patrimoniales, se trata de una forma difícil de visibilizar al desarrollarse en el ámbito privado de la díada, así mismo incide en la toma de decisiones y desenvolvimiento de la víctima en la sociedad.

Tipo de violencia económica: control y pérdida de libertad

Como lo señala Novoa (2016), esta clase de agresiones no son fáciles de percibir, pues se enmarcan en escenarios tradicionales donde los hombres han tenido mayor control sobre la mujer. En estos casos, algunos hombres utilizan su poder económico para controlar a su pareja, supervisan y limitan las decisiones que ella pueda tomar en temas personales y en asuntos propios del hogar.

Una forma común en que se presenta esta violencia es cuando la madre tiene bajo su cuidado a los hijos y el padre se desentiende por completo de los gastos de ellos: "no me está aportando para la alimentación de mis hijos porque solo me dice que no tiene plata y me toca buscar la manera para poder brindarles un almuerzo" (Alba, 26 años, mayo 2017). En ocasiones las víctimas de esta forma de violencia no reconocen este abuso económico como violencia. Otra forma de presenciar la violencia económica es cuando el hombre quiere imponer utilidad en el dinero que pertenece a la mujer: "me empezó a tratar mal porque yo no le dejaba sacar plata mía para comprar más bazuco" (Ingrid, 21 años, agosto 2017) o, simplemente, el hombre es quien manipula las acciones de su pareja "no me deja tranquila, no me deja trabajar y no le da nada al bebé, ni la cuota alimentaria" (Amanda, 37 años, enero 2017).

En otros casos, el hombre utiliza el poder que tiene en el hogar para controlar a su pareja, hasta llegar al punto de prohibir acceso a la alimentación "él esconde gran parte del mercado y hace comida muchas veces para él solo" (Inés, 38 años, enero 2017). El hombre busca la forma de intimidar y amenazar a la mujer, buscando 
Tibaná-Ríos, Arciniegas-Ramírez y Delgado-Hernández

perjudicarla para lograr que ella dependa totalmente de él: "voy a ir a su empresa a hacerle escándalo para que la echen del trabajo y así no pueda estudiar y tenga que seguir sometida a mí, le voy a dañar el caminado" (Andrea, 32 años, febrero 2017). Finalmente, chantajear a nivel sexual a la pareja, se encuentra usualmente en los relatos investigados: "me dijo que como yo no se lo daba, o sea que no teníamos relaciones sexuales, no me mantenía más, que no comiera del mercado" (Luzmila, 40 años, 20 junio 2017).

Esta violencia representa una pérdida de libertad tanto en acciones cotidianas como en grandes movimientos financieros, a su vez incide en la dificultad para la toma de decisiones en otras esferas de la vida de la víctima, el temor y el miedo se enraízan en el modo y estilo de vida de la persona.

\section{Tipo de violencia sexual: ¿es mi cuerpo, su territorio?}

Probablemente, durante las relaciones de pareja se asuma que es una obligación corresponder en las relaciones sexuales; en la mayoría de los casos revisados, se observa que los cónyuges, hombres, buscan intimidad con su compañera, así ella no se encuentre en condición de tener encuentros sexuales, y se cree que es el deber como pareja satisfacer la necesidad sexual del hombre, porque es su esposo o su compañero, como lo menciona la psicóloga Noseda (2015):

Las mujeres tienden a creer que dentro de la relación afectiva estable, no existe la posibilidad de negarse a tener relaciones sexuales con absoluta comodidad y normalidad. Al contrario, sienten que lo normal es tener relaciones sexuales, aunque muchas veces no quieran.

En ocasiones cuando la mujer se resiste, él reacciona de manera violenta y por ende la víctima, en contra de su voluntad, corresponde a su pareja, simplemente para evitar conflictos, como se muestra en los siguientes relatos: "me obliga a tener relaciones sexuales con él o si no me empieza a pelear" (Carmen, 25 años, Diciembre 2017), "cuando no quiero tener sexo él me obliga y me dice que él no es el mozo que él es mi marido y tengo que hacerlo y me empieza a golpear" (Luceli, 43 años, mayo 2017). Se puede resaltar que este tipo de violencia se ejerce acompañada de otras violencias.

La violencia sexual se presenta en diferentes manifestaciones, una de ellas es por medio del manoseo a la mujer: "él siguió manoseándome, yo le rogué que por favor hacía lo que él quisiera pero que me soltara" (Leidy, 31 años, Julio 2017); el cónyuge se siente en el derecho de realizar este acto con su compañera, sin embargo, el manoseo no se presenta mutuamente o no es correspondido, la mujer pasa a un nivel de incomodidad mientras el hombre está complaciéndose con ella. 
Forzar relación sexual es otra forma de esta violencia, y se realiza con el uso de la fuerza del hombre con su pareja: "él me empezó a tocar y a bajar la ropa, el pijama y la ropa interior y como yo le dije que no, empezó a tratarme mal y de todas formas me agredió sexualmente" (Mery, 59 años, agosto 2017). Este llega hasta el punto de las agresiones físicas contra la mujer y, pese a ser consciente del daño causado, no cesa este agravio sexual: "él me tiró al piso y me obligó a tener relaciones con él aun estando golpeada" (Flor, 38 años, abril 2017).

El abuso sexual, particularmente se evidencia mediante el chantaje o también con malos tratos verbales hacia la mujer, así: "En oportunidades íntimamente le refiero a él que no quiero tener relaciones, pero él al igual las sostiene, cabe confirmar que, sin forcejeo, pero empieza a agredirme verbalmente diciéndome que soy una vaca muerta..." (Jessica, 26 años, noviembre 2017).

Otra manifestación con la que se presenta la violencia sexual es cuando el hombre decide violar a su pareja. En los hallazgos se denota que no todas las mujeres reconocen estos actos como violación, relatos como: "me sentí violada" (Carolina, 38 años, junio 2017), son pocos; claramente, cuando ella reconoce estos actos como violencia, se desnaturalizan las "obligaciones conyugales" de lo contrario, la mayoría de las mujeres siguen creyendo que permitir que su pareja acceda a ella sexualmente, es lo que corresponde. Valle-Ferrer (2011) indica que las secuelas tanto físicas como mentales en las mujeres violentadas sexualmente son permanentes (p.24).

\section{Tipo de violencia emocional: heridas en el alma}

En los sucesos de violencia de género contra la mujer, el área emocional es una de las más afectadas, dado que la violencia emocional se expresa hacía la víctima mediante el lenguaje verbal o gestual, representado mayormente por los insultos (SanmartínEsplugues, 2007).

Se hallaron testimonios, con un alto contenido de violencia emocional y escenas, donde el hombre en aparente superioridad, se asigna la potestad de juez, y los insultos se convierten en improperios contra la mujer, como: "perra, malparida no vales la pena gonorrea, triple hijueputa, que me meta y me tire del salto del Tequendama" (Xiomara, 24 años, mayo 2017), se hace uso de palabras como: "malparida", semejante a "mal nacido o hijo de mala madre", e "hijueputa", para referirse a "hija de puta", términos que desacreditan a las mujeres específicamente. De este modo se alimenta su ego, fomentando el miedo, tras la fachada del respeto merecido, "que lo respete que él es un varón, y se respeta, [...] me dijo palabras como, hijueputa, boba, maricona, niña" (Ángela, 27 años, junio 2017). 
Entre las manifestaciones, como bromas hirientes, trayendo a colación el violentómetro, están al inicio, por ser "sutiles", pero desatan más agresiones. En caso de excompañeros o exesposos, las agresiones son: "vino a mi casa a tratarme mal, a burlarse de mí" (Rosario, 60 años, 30 mayo 2017), donde las burlas se convierten en armas de venganza certeras. Respecto a parejas que conviven, persiste la sátira hacia el aspecto corporal: "se burla de mi cuerpo que, por contextura gruesa, que por mis pecas" (Luz, 37 años, mayo 2017). Cabe mencionar la influencia de medios de comunicación en los estereotipos: "él me dijo que parecía Amparo Grisales en versión gorda, que mire como tiene esa boca parece que se la hubiera mamado a alguien" (Ana, 52 años, febrero 2017), son lesiones profundas e invisibles, en la percepción de la mujer para consigo misma.

También se evidencia ridiculizar, ofender, aunque más crítica que las bromas, la intención persiste, pero se realiza de una manera intensa, ocasionalmente frente a personas cercanas o frente a los hijos en común: "llamó a mis 2 hijos y les dijo que miraran la vagabunda que tenían como mamá, que venía toda arrastrada y que venía de una residencia por eso era por lo que no venía bien tomada, según él" (Marcela, 38 años, enero 2017). El propósito es cambiar la percepción de los demás hacia ella, dando por sentado un presunto hecho desleal al hombre y por ende a la familia, o, en otros casos, el agresor hace hincapié en la "inutilidad" de la mujer: "que sirvo para nada, que soy una vieja fea" (Lilia, 34 años, junio 2017).

El acto de culpabilizar evoca a la figura masculina del juez, nuevamente, pero esta vez, dictamina una sentencia clara: "culpable", de modo que, añade una carga de responsabilidad a la mujer sobre el acto violento sucedido: “ipor qué no hace caso, loca? por su culpa son los problemas" (Yuli, 27 años, julio 2017). En este relato se puede ver que el hombre respalda su agresividad al no percibir obediencia por parte de la mujer; en las disputas de excompañeros o exesposos se hallan testimonios así: “cuando mi excompañero me agrede física verbal o psicológicamente, después se arrepiente dice que fui yo la que tuvo la culpa por lo agredido" (Bibiana, 34 años, mayo 2017).

Un aspecto desventajoso en relaciones conyugales es chantajear para conseguir un objetivo a como dé lugar; si la pareja convive y la mujer depende económicamente del agresor agrava la situación, por ejemplo: “Él dice que me apoya para estudiar o trabajar, pero en el momento de iniciar un proyecto él se opone y me manipula con el niño" (Francy, 25 años, junio 2017). El hombre se encarga de poner en balanza las situaciones y priorizarlas a su parecer, exigiendo implícitamente que se encargue del hogar; en las exparejas los hijos son excusa del victimario para maniobrar la relación respecto al retorno de la unión conyugal: 
Tibaná-Ríos, Arciniegas-Ramírez y Delgado-Hernández

Me llamó según él a entregarme el dinero de la deuda de la pensión y del uniforme del colegio del niño, pero él me dijo que no me daba nada si yo no me acostaba con él, yo no accedí. (Dana, 26 años, marzo 2017).

Por otro lado, ignorar o ejercer la ley del hielo, rompe los esquemas del abuso a través de la palabra o del insulto, pero, es una estrategia igual de letal, donde la displicencia, frialdad, prima considerablemente en los cónyuges, ya que es una ruptura absoluta a la convivencia habitual, notada en el siguiente relato:

Llegó por la noche, que se iba a aplicar una inyección y que se iba a ir, que tenía un examen, a las 10 pm se fue y llegó a las 3 am, se acostó y al día siguiente se bañó y se fue; tipo 11 de la noche él llegó a alistar sus cosas para el día siguiente. (Wendy, 22 años, marzo 2017).

\section{Tipo de violencia psicológica: "no te voy a dejar en paz"}

El anterior tipo de violencia, se asocia con la violencia psicológica, dado que, el constante recibimiento de estas agresiones deriva en alteraciones psicopatológicas (Duque y Vieco, 2012); cabe aclarar, que es complejo determinarlas mediante el análisis de discurso y contenido, pero se hace explícita en expresiones como: " [...] yo tengo mucho miedo que él me agreda otra vez y yo vivo muy atemorizada de él"; o frases como "vivo muy atemorizada" (Mariana, 25 años, enero 2017) reflejan que el maltrato trasciende del emocional, a perturbar el estado mental de la mujer. La psique requiere tanto cuidado como el cuerpo humano, si los golpes causan lesiones, asimismo, repetidas agresiones, por ejemplo: “[...] duré 15 años de maltrato de parte suya y tomé la decisión de separarme. Yo como persona me siento mal salir a la calle y que él me haga daño" (Susana, 43 años, junio 2017).

El daño psicológico causa sufrimiento a la mujer, a través de conductas intencionadas que tienden a desvalorizar (Falcón-Caro, 2002), corroborado mediante la acción de descalificar, donde mujeres señalan: "me agrede con palabras delante de mis hijos como vagabunda, [...] que tengo mozo y que soy una perra desagradecida, me pordebajea delante de ellos, no me deja ni hablar, me calla la boca" (Leidy, 28 años, julio 2017); también cohibir con órdenes su expresión, perturbando la personalidad de la mujer: "que no soy una señora, que yo no hablo si no estupideces y bobadas" (Gina, 34 años, junio 2017). En esta narración el agresor resta valor a la opinión de la víctima, igualmente, le quita el "título" de "señora", al cual le atañe un significado simbólico.

Hay determinados actos violentos, fuera del hogar, como humillar en público, situación enfocada en que las personas cercanas cambien su conducta hacia ella: “Se la 
pasa hablando con todo el mundo de mí, que soy la peor" (Mónica, 26 años, julio 2017), o relatos así: "me pordebajea delante de todo el mundo" (Roxana, 45 años, febrero 2017), los cuales muestran las instancias a las que el hombre recurre, para hacer sentir mal a la mujer y ratificar el alcance atribuido a su autoridad, contribuyendo negativamente a que la persona esté prevenida y a merced del agresor para que no se repitan los sucesos mencionados.

La presión masculina ejercida sobre la mujer desmesuradamente avanza, donde actos como encerrar, aislar, se basan en limitar la comunicación con el mundo exterior: "no tengo vida social no puedo visitar a mi familia" (Julia, 55 años, noviembre 2017), impidiendo la interacción de familiares con la víctima, para que no tenga contacto con alguien que desestabilice su relación de poder, o como manera coercitiva de imponer su autoridad. Un aspecto particular, por el cual se ejerce el encierro es para que el evento de violencia no sea denunciado, mayormente si es mediante golpes evidentes: "aparte de todo no me dejaba salir del conjunto hasta que no se me quitaran los moretones y la fisura que me dejó en el rostro" (Cecilia, 38 años, junio 2017).

Celar, es una manera de aturdir a la mujer e influir sobre sus acciones, mediante reclamos suscitados por la sospecha: "porque tenía unos celos posesivos de que yo no podía hablar con nadie ni nada porque siempre me decía que yo tenía mozo" (Sophie, 20 años, abril 2017); de este modo, restringe sus relaciones sociales e interacciones cotidianas, por ejemplo: "había un señor y él dijo que me estaba coqueteando y sacó un puño y me pegó" (Rubí, 39 años, agosto 2017). La intensidad y frecuencia de estas agresiones desembocan en celos obsesivos, patológicos, denominados celotipia, representados con amenazas como: “Dice que por encima de cualquier cosa matará si alguien se me arrima, sus celos y su comportamiento son demasiado" (Clara, 32 años, marzo 2017). Esto reitera la idea machista de que la mujer es una posesión exclusiva de su compañero o excompañero.

La acción de controlar y prohibir, engloba distintas conductas del agresor para permear en las diferentes áreas que involucran a la mujer, sea, social, digital, e incluso en la expresión del vestuario: "me iba a una cita médica y me dijo que esa ropa interior no" (Isabel, 47 años, julio 2017), regularmente, se usa la manipulación para influir en las decisiones por parte de la mujer, aludiendo frecuentemente al rol que se le atribuye en casa, con los hijos:

Tenía una entrevista laboral y ese fue el motivo, porque él me dice que yo lo voy a dejar, que tengo mozo, que soy de él, que para qué estudiar, que me dedique al niño, que para qué trabajar si él me da todo. (Diana, 25 años, junio 2017). 
Actualmente el apogeo de las redes sociales y medios electrónicos de comunicación, suma maneras de violencias a este fenómeno: "agarra mi celular y llama a todos mis contactos a tratarlos mal, me borra los contactos hombres que tengo" (Lina, 25 años, abril 2017).

La estrategia por excelencia, para afectar la salud mental de la mujer es infundir miedo, principalmente intimidar, amenazar, manifestación que aprehende el lenguaje verbal y no verbal para operar (Duque y Vieco, 2012). En los testimonios se hallan escenarios donde persiste la violencia subsecuente y por lo tanto un antecedente que coacciona a la mujer para reaccionar en sumisión ante el agresor, con el temor de que este hecho vuelva a ocurrir: "amenazándome que me iba a golpear, como siempre lo hace cuando se enoja, o le hago algún reclamo por algo, diciéndome que si le decía algo más me iba a dar una paliza" (Sandra, 34 años, octubre 2017), y en interacciones de excompañeros o exesposos, la amenaza es constante en torno a los bienes: "me dijo que me iba a demandar que me iba a dejar sin nada" (Cristina, 32 años, abril 2017).

Un elemento peculiar, encontrado en esta manifestación a partir de las narrativas, corresponde a la amenaza de dañar el físico de la mujer, como si fuera una posesión para hacer o deshacer: "que me iba a dar un machetazo en la cara para que nadie me mirara" (16 septiembre 2017), "amenaza o intenta cortarme el cabello" (Samantha, 26 años, junio 2017), y por último, persiste la advertencia del uso de ácido: “Crea lo que quiera sapa hijueputa a ver si con la cara llena de ácido va a levantar perra" (Dany, 23 años, noviembre 2017).

Así mismo amenazar de muerte, siembra la duda e incertidumbre, respecto a consumar el daño expresado contra la vida de la mujer: "me dijo que iba a ir a mi lugar de trabajo y me iba a meter unas puñaladas, que me iba a matar, yo le dije que lo iba a denunciar y me respondió que le importaba un culo" (Alejandra, 22 años, septiembre 2017). La defensa de la mujer es apelar a las autoridades, pero al victimario no le importa sobrepasarlos con su actitud retadora: "todo el tiempo recalcándome que no le importa irme a pagar, que prefería matarme" (Sonia, 22 años, diciembre 2017). Se continúan hallando frases como: "por encima de lo que sea se lo juro, que si no es para mí la mato" (Clara, 32 años, marzo 2017), que muestran la posesividad obsesiva.

Las amenazas, cambian su tonalidad más oscura cuando se evidencia el amenazar con armas, ya que, se traslada el daño percibido psicológicamente a acciones contundentes en el ámbito físico, por ejemplo: "ya volvió a sacarme cuchillo y me lo ha puesto en la garganta" (Rosa, 56 años, enero 2017); en este relato es de resaltar, primordialmente, que no es la primera vez que se vive dichas amenazas. El uso de armas de fuego no es tan frecuente: "amenazándome con arma de fuego, apuntándome y colocándome el arma en el cuello" (Natalia, 32 años, diciembre 2017). 
Tibaná-Ríos, Arciniegas-Ramírez y Delgado-Hernández

\title{
Tipo de violencia física: pendiendo en sus manos
}

La violencia física, es esbozada por la ley, como el daño a la integridad corporal. Esta frase, tiene un trasfondo y diversas manifestaciones contenidas, lo que queda claro, es el atentado hacia la vida de la mujer cuando se efectúa:

\begin{abstract}
Se me acerca, me coge a ahorcarme con el brazo, en el forcejeo yo trato de salirme hacia abajo, es cuando él se me sube encima de las caderas, pegándome puños en la cabeza, me tiene sometida sobre el piso, me coge del cabello y me hala hacia arriba y después hacía abajo, que es cuando me pega en la frente contra el piso. (Laura, 26 años, septiembre 2017).
\end{abstract}

En el relato previo, es de resaltar el modus operandi, encontrado en los testimonios, y es la reducción de la mujer mediante la asfixia, de esta manera se disminuye la fuerza y la capacidad de defensa. Así lo enuncia Falcón-Caro (2002), es la acción no accidental que incluye fracturas, palizas entre otros, por ejemplo: "me agredió causando fractura en el tabique, golpes en la cara, labios rotos" (Sara, 21 años, abril 2017).

Se menciona al inicio de este apartado que la violencia trae consigo múltiples manifestaciones, entre ellas, la acción de patear, frecuentemente encontrada en las narraciones, donde una vez sometida la mujer y en el suelo o donde el hombre esté sobre ella, el uso de los pies para infringir dolor es certero: "mi marido empezó a golpearme en frente de mi hija, pegándome patadas en todo el cuerpo, cachetadas, puños, [...] continuó pegándome hasta que se cansó" (Rocío, 20 años, diciembre 2017). La impresión de toda la fuerza y energía física del agresor, para que termine con los golpes debido a su agotamiento, permite entrever la sevicia consumada en dicha manifestación. En el escenario de la agresión física, no son excluyentes entre sí sus diferentes manifestaciones y se pueden presentar varias en un episodio.

Cachetear implica un golpe propinado en la cara con la mano, en algunos relatos se halla: “yo me arrodillé y fue cuando me abofeteo" (Lucía, 42 años, marzo 2017); en esta circunstancia, el hombre ve la oportunidad de efectuar esta lesión ante la sumisión de la mujer, continuando con manifestaciones como empujar, jalonear, reacciones que tienen elementos semejantes. En las narraciones, ocasionalmente los empujones se daban para arrinconar, conducirla violentamente a un lugar y así continuar la agresión: "entonces me tomó del pelo y me empujaba para el cuarto mientras me agredía" (Silvia, 42 años, marzo 2017), o para quitar, remover a la mujer de su camino: “él me pegó un empujón y no tenia de dónde cogerme y rodé por las escaleras, caí de espalda y se me fue el aire, yo pedía auxilio y él me decía que no fuera showsera" (Heidi, 26 años, mayo 2017). En este fragmento, el agresor no la ayuda y justifica su omisión al decir que está fingiendo. 
Tibaná-Ríos, Arciniegas-Ramírez y Delgado-Hernández

Respecto a jalar o halar a la mujer, esto se efectúa sujetando el cabello para así someter: "yo estaba adentro, me cogió del cabello para pegarme" (Alicia, 34 años, mayo 2017). Es de mencionar además, los episodios que incluyen actos de pellizcar, como uso de las uñas para causar lesiones: "me empujó, me pegó y me arañó la cara" (Sandra, 28 años, abril 2017); o hechos como escupir también denotan un menosprecio en señal de odio o repudio: "diciéndome que yo soy una perra, zorra que no sirvo para nada, que soy una malparida sucia que le doy asco y me escupe" (María, 34 años, junio 2017). Tal como lo menciona Valle-Ferrer (2011), en los testimonios de mujeres víctimas de violencias se muestra que la mayoría de las agresiones físicas se ejercen seguidas de la presión psicológica en el incidente, o un resultado del mismo (p. 22).

Un elemento hallado en los expedientes de medida de protección es el soporte de la agresión, validado por el Instituto Nacional de Medicina legal, quien a través de sus profesionales comprueba dichas lesiones y emite un concepto e incapacidad que permite entrever la magnitud del daño físico, sin secuelas o con secuelas médico legales a determinar, siendo un recurso que sustenta la versión de la víctima: "empezó a agredirme y me remitieron para medicina legal y allí me dieron 7 días de incapacidad" (Soraya, 19 años, enero 2017).

\section{Presencia institucional en casos de violencia contra la mujer}

La violencia contra la mujer en sus múltiples tipos y expresiones bien sea en acción $u$ omisión, representan una vulneración directa a sus derechos humanos, ya que proporcionan un daño sistemático a todas las áreas de su desarrollo, provocando en ella secuelas psicológicas, físicas y emocionales duraderas. La respuesta o contención a esta problemática data en la actuación Estatal y la visión intersectorial basada en los tratados internacionales de los cuales Colombia es parte; para ello se disponen de políticas y programas que abarcan tanto la atención y prevención de las violencias contra la mujer en el ámbito público como privado. Sin embargo, las cifras de violencia oficiales y aquellas no registradas confrontan las herramientas gubernamentales para el tratamiento de este improperio.

Las entidades públicas como las Comisarías de Familia, que prestan sus servicios a las víctimas de violencia, reciben los casos y los direccionan de acuerdo a lo dictado por la legislación de violencia intrafamiliar, sin dar diferencia alguna a la violencia de género invisibilizada entre los contextos de violencia intrafamiliar; es decir, que resulta siendo equivalente a cualquier caso de violencia intrafamiliar y desde allí parte una negligencia estatal en contra de los derechos de la mujer, en la medida en que no se establece una ruta entrelazada de restablecimiento integral de los derechos vulnerados de las mujeres víctimas de violencia. 
La política pública de mujer y equidad de género municipal señala: "los instrumentos de derechos humanos de la mujer rompen con el sistema de jerarquías, de subordinación y discriminación entre los géneros comprometiendo al Estado y a la sociedad en general" (Acuerdo 25 de 2015, p. 2). Así se denota que el Estado es incluso un victimario de la violencia de género contra la mujer, puesto que la presencia latente de dicha violencia muestra la ineficacia en la atención y las actuaciones que brindan las instituciones competentes. Como máximo regulador en la sociedad, no se evidencia claridad y aplicabilidad de los tratados internacionales al contexto colombiano, por el contrario, propaga y valida el sistema patriarcal de manera tácita en esferas macro que permean los diferentes ámbitos incluidos el familiar, el conyugal, así como instituciones que oprimen a la mujer bajo la premisa cultural y social del paternalismo.

\section{Conclusiones}

El proceso de investigación permitió reafirmar la premisa hipotética, acerca de la invisibilización de los tipos y manifestaciones de la violencia de género inmersos en el contexto de violencia intrafamiliar, como es ratificado por Lafaurie (2013): “La violencia de género se puede manifestar a través de la violencia intrafamiliar o doméstica, la violencia de pareja o conyugal, el maltrato infantil y las distintas formas de violencia sexual" (p. 99).

Es importante tanto en el marco social como profesional develar el significado no 141 solo de los actos prácticos sino del mismo lenguaje con que se reportan los hechos violentos (manifestados en este artículo por medio de tipos y manifestaciones), con el fin de vislumbrar un proceso de intervención pertinente, ético y contextualizado. De esta forma se busca dar respuesta a un flagelo personal y social, con causales respecto al género que son radicales, es decir que van más allá de la búsqueda del establecimiento de condiciones equitativas entre hombres y mujeres, sino que trasciende a una construcción histórica y cultural reproducida por medio del lenguaje.

Por ello en aras de una intervención pertinente, se considera imprescindible que los funcionarios y funcionarias públicas, y el equipo de profesionales sociales especializados en la detección, atención y activación de rutas de atención ante la violencia de género, incorporen en su quehacer profesional la perspectiva de género como un enfoque teórico y práctico para develar las formas de violencias legitimadas culturalmente, agregando el uso complementario y esencial del violentómetro. También es importante en un asunto de corresponsabilidad, fomentar el uso de lenguaje no sexista, dando cuenta de las expresiones naturalizadas en la cotidianidad y de este modo influir gradualmente en las actitudes sociales para contrarrestar elementos estructurales en el problema. 
Por otro lado, la violencia de género no es específica en los procesos realizados por la comisaría de familia, donde se generalizan los hechos de agresión en términos de violencia intrafamiliar, apelando a los parámetros establecidos legalmente. Por lo tanto, es válido afirmar que la legislación colombiana está restringida frente a la tipificación del hecho violento que se registra en las comisarías de familia del municipio lo cual genera una limitante respecto a la defensa de los derechos de la mujer.

Es de suma relevancia que las instituciones prestas a atender este tipo de casos, como la comisaría de familia, una entidad que constituye la puerta para el acceso a la justicia en casos de violencia intrafamiliar, articulen las medidas de sensibilización, prevención, protección y atención contenidas en la Ley 1257 de 2008 a favor de las mujeres, para fortalecer procesos institucionales y así restablecer integralmente los derechos de las mujeres víctimas de violencias. Esto implica una articulación del equipo interdisciplinar en la recepción o primera atención del caso, así como articulación a nivel interinstitucional, que proporcionen la seguridad oportuna a las mujeres víctimas y la prontitud en la resolución del conflicto, y el interés para que los procesos judiciales no sean dilatados y sea violentada la mujer institucionalmente también. Aunado a lo anterior, es imperativo brindar espacios de real participación, poder y decisión a la mujer como paso vital para una real equidad de género.

\section{Referencias bibliográficas}

Cifuentes-Gil, R. M. (2014). Diseño de proyectos de investigación cualitativa. Buenos Aires, Argentina: Ediciones Novedades Educativas.

Concejo Municipal de Soacha. (25 de agosto de 2015). [Acuerdo 25 de 2015]. Recuperado de https://www.alcaldiasoacha.gov.co/phocadownloadpap/Normatividad/normatividad_mu nicipal/ACUERDOS/CONCEJO_MUNICIPAL/Acuerdo $\% 2025 \% 20 \mathrm{de} \% 202015 \% 20 \mathrm{PP} \% 20 \mathrm{M}$ ujer $\% 20 \mathrm{y} \% 20 \mathrm{Genero} . p d f$.

Concejo Municipal de Soacha. (30 de mayo de 2016). Plan de desarrollo social, económico, ambiental y de obras públicas del municipio de Soacha: 2016-2019. [Acuerdo 13 de 2016].

Congreso de Colombia. (04 de diciembre de 2008). [Ley 1257 de 2008]. Do: 47.193.

Congreso de Colombia. (24 de julio de 2000). Código Penal. [Ley 599 de 2000]. Do: 44.097.

Corporación Sisma Mujer. (2010), Reparación para las mujeres víctimas de violencia en el conflicto armado. Una aproximación a la formulación de criterios para su determinación. Bogotá. Corporación Sisma Mujer.

Duque, H., y Vieco, P. (2012). Violencia Intrafamiliar. Bogotá: San Pablo.

Falcón-Caro, M. (2002). Malos tratos habituales a la mujer. Bogotá: Universidad del Externado de Colombia.

Gálvez-Montes, C. (2011). Violencia de Género. Terrorismo en Casa. España: Formación Alcalá. 
Tibaná-Ríos, Arciniegas-Ramírez y Delgado-Hernández

Gómez, C., Murad, R., y Calderón, M.C. (2019). Historias de violencia, roles, prácticas y discursos legitimadores. Violencia contra las mujeres en Colombia 2000-2010. Recuperado de https:// www.minsalud.gov.co/sites/rid/Lists/BibliotecaDigital/RIDE/INEC/INV/7\%20\%20VIOLENCIA \%20CONTRA\%20LAS\%20MUJERES\%20EN\%20COLOMBIA.pdf.

Hernández-Sampieri, R., Fernández-Collado, C., y Baptista-Lucio, M. (2014). Metodología de la investigación. Colombia: McGraw Hill.

Hurtado de Barrera, J. (2010). Metodología de la investigación: guía para una comprensión holística de la ciencia. Caracas, Venezuela: Quirón Ediciones.

Romero-Quevedo, J.H. (2017). Comportamiento de las lesiones por violencia intrafamiliar. Colombia, 2017. Forensis. Datos por la vida. Volumen 19(1), 171-254 Recuperado de https:// www.medicinalegal.gov.co/documents/20143/262076/Forensis+2017+Interactivo.p df/0a09fedb-f5e8-11f8-71ed-2d3b475e9b82.

Instituto Politécnico Nacional de México. (2009). Violentómetro. Recuperado de https://www.ipn.mx/genero/materialesdeapoyo/v-separador.pdf.

Lafaurie, M. (2013). La violencia intrafamiliar contra las mujeres de Bogotá: una mirada de género. Revista colombiana de enfermería, 99, 98-111. Recuperado de https://revistacolombianadeenfermeria.unbosque.edu.co/article/view/550/143.

Noseda, J. (2015). Violencia sexual en tu propia cama: la agresión sexual en pareja. El Dínamo. Recuperado de https://www.eldinamo.cl/blog/violencia-sexual-en-tupropia-cama-la-agresion-sexual-en-pareja/.

Novoa, J. (2016). Lo que debe saber de la violencia económica contra la mujer. Asuntos legales. Recuperado de https://www.asuntoslegales.com.co/consultorio/lo-quedebe-saber-de-la-violencia-economica-contra-la-mujer-2378351.

Organización Mundial de la Salud. (2020). Mutilación genital femenina. Recuperado de https:/ / www.who.int/es/news-room/fact-sheets/detail/female-genital-mutilation.

Organización Panamericana de la salud. (1998). La ruta crítica que siguen las mujeres afectadas por la violencia intrafamiliar. Washington: OPS y OMS.

Quintero-Velásquez, A.M. (2007). Diccionario especializado en familia y género. Buenos Aires: Hvmanitas.

Ricoeur, P. (2006). Teoría de la interpretación: discurso y excedente de sentido. México: Siglo XXI editores. Recuperado de http://mastor.cl/blog/wpcontent/uploads/2015/08/ Ricoeur.-Teoria-de-la-interpretacion.-Siglo-XXI.pdf.

Rodríguez-López, M., Jiménez-Torrado, C., Hamodi-Galán, C., Blanco-Ocampo, M., Salazar-Cohen, A.M., y Morad de Martínez, M. (2017). Violencia intrafamiliar desde la perspectiva de género: discurso de víctimas y agresores. Documentos de trabajo social Revista de trabajo y acción social, (59), 233-258.

Sanmartín-Esplugues, J. (2007). ¿Qué es violencia? Una aproximación al concepto y a la clasificación de la violencia. Daimon Revista Internacional De Filosofía, (42), 9-21.

Thomas, F. (2014). Conversación con un hombre ausente. Bogotá: Icono.

Vaccaro, S. (noviembre, 2018). La justicia como instrumento de la violencia vicaria: la ideología del pretendido "SAP" y la custodia compartida impuesta. En Nuevas jornadas de 
Tibaná-Ríos, Arciniegas-Ramírez y Delgado-Hernández

Violencia de Género. El patriarcado en la justicia. Comisión de Igualdad del Consejo de Cultura Galega. Galicia, Santiago de Compostela. Recuperado de http://consellodacultura.gal/mediateca/extras/CCG_ac_2018_novasformasviolenci axenero_soniavaccaro.pdf.

Valle-Ferrer, D. (2011). ¿Qué es la Violencia en la familia? En D. Valle-Ferrer, Espacios de libertad: Mujeres, violencia doméstica y resistencia (pp. 13-33). Buenos Aires: Espacio editorial.

Recuperado

de

http://www.trabajosocial.unlp.edu.ar/uploads/docs/valle_ferrer_2011_violencia en_la_familia.pdf.

Varela, N. (2008). Feminismo para principiantes. Barcelona, España: Ediciones B. S. A. Recuperado https://kolectivoporoto.cl/wp-content/uploads/2015/11/VarelaNuria-Feminismo-Para-Principiantes.pdf.

Zúñiga-Espitia, G. (2005). Diccionario Filosófico Nika. Bogotá: Nika Editorial. 


\section{OTROS ARTÍCULOS DE PROSPECTIVA No. 30 DE 2020}

\section{EDITORIAL}

Coherencia, integridad y vida cotidiana

Luz Mary Sánchez-Rengifo

\section{ARTÍCULOS}

Trabajo Social y medios de comunicación: perspectivas y posibilidades de encuentro Social

Mercedes Muriel-Saiz

Maribel Martín-Estalayo

Seguridad, afectos y familias. Obstáculos en el proceso de reintegración de personas desmovilizadas de grupos

armados en Santander, Colombia

Jakeline Vargas-Parra

Ángela María Díaz-Pérez

Priscyll Anctil-Avoine

Reflexividad sobre la intervención profesional en duelo con población afectada por el conflicto armado en Colombia

María Cénide Escobar-Serrano

Maritza Charry-Higuera

Natalia Ramírez-Moncada

Ser mujer indígena, náhuatl, casada, migrante, sin trabajo remunerado: una realidad en los albergues jornaleros agrícolas en Colima, México

Nancy Elizabeth Molina-Rodríguez

Tipos y manifestaciones de la violencia de género: una visibilización a partir de relatos de mujeres víctimas en Soacha, Colombia

Diana Carolina Tibaná-Ríos

Diana Alejandra Arciniegas-Ramírez

Ingrid Julieth Delgado-Hernández

Análisis de necesidades en familias monoparentales con jefatura femenina usuarias de servicios sociales de atención primaria en España

Celia María Fernández-Martínez

Manuela Avilés-Hernández

Experiencias de intervención de trabajadoras sociales con trabajadores sexuales masculinos en Bogotá, Colombia Johan Arturo Barrera-Castellanos
Condiciones laborales de trabajadores sociales en hospitales públicos en la provincia de Mendoza,

Argentina

Cecilia Amalia Molina

Yanina Noemi Roslan-Angeloni

Analía Graciela Correa

Viviana Elena Varela

Gubernamentalidad neoliberal: miradas desde las intervenciones del Trabajo Social en el Gran La Plata, Argentina

Paula Mara Danel

Marcela Claudia Velurtas

Agustina María Favero-Avico

Educación superior en Trabajo Social en Chile y formación para la intervención en situación de calle. Desafios desde la evaluación que interventores hacen de sus procesos de práctica pre-profesional

Carlos Alejandro Andrade-Guzmán

Ignacio Andrés Eissmann-Araya

Educación en Derechos Humanos para el Trabajo Social en Chile: una mirada desde los estándares

internacionales

Lury Soledad Reyes-Pérez

Vivianne Soledad Hasse-Riquelme

Luis Marcelo Silva-Burgos

Arriesgar y preservar la vida: derechos humanos, conflicto sociopolítico armado y Trabajo Social en Colombia

Cristian Sebastián Castaño-Orozco

Ricardo Patiño-Martínez

\section{IN MEMORIAM}

Cristina Bautista Taquinás. Mujer indígena Nasa, Trabajadora Social, lideresa del norte del Cauca, Colombia

Alba Nubia Rodríguez-Pizarro

Lady Johanna Betancourt-Maldonado
ARTISTA INVITADO
MALA JUNTA KLAN
Alejandra Gutiérrez-Cárdenas

\section{PROSPECTIVA}

